\title{
Perang Global Melawan Terorisme dalam Perspektif Sekuritisasi
}

\author{
Dina Yulianti \\ Program Studi Hubungan Internasional Universitas Padjadjaran \\ dinay3007@gmail.com
}

\section{ABSTRACT}

The Global War on Terrorism has continued 17 years since 2001 but has not made the world safer. Terrorist acts continue to occur in various countries, even new terrorist groups have emerged, including IS (Islamic State). US presidents from the George W. Bush to Trump continue to declare terrorism as a threat for national security and world security. This article discussed this phenomenon using securitization theory to answer the question of whether terrorism really threatens US security or is there other factors behind the continuity of GWOT policy? The study found that although acts of terrorism did caused many victims, the casualties of GWOT are much greater. The US goal in launching GWOT is to frighten the world (using the 'politics of fear') so that countries are willing to join GWOT's military operations. This war is very profitable for the US military industry and escalate US domination in the world.

Keywords: Al Qaida, 911, global war on terrorism, securitization, US domination

\section{ABSTRAK}

Perang Global Melawan Terorisme (GWOT) telah berlangsung 17 tahun sejak 2001 namun belum berhasil membuat dunia lebih aman. Aksi-aksi teror terus terjadi di berbagai negara, bahkan kelompok-kelompok teroris baru bermunculan, antara lain IS (Islamic State). Presiden AS sejak era George W. Bush hingga Trump terusmenerus menyebut terorisme sebagai ancaman bagi keamanan nasional dan keamanan dunia. Dalam artikel ini, penulis akan membahas fenomena ini dengan menggunakan teori sekuritisasi, untuk menjawab pertanyaan apakah terorisme 
benar-benar mengancam keamanan masyarakat AS atau adakah faktor-faktor lain yang melatarbelakangi keberlanjutan kebijakan GWOT AS? Penelitian ini menemukan bahwa meskipun aksi-aksi terorisme telah menjatuhkan banyak korban, korban yang jatuh akibat GWOT jauh lebih besar. Tujuan AS dalam melancarkan GWOT adalah untuk menakuti-nakuti publik dunia (politics of fear) sehingga negara-negara bersedia bergabung dalam berbagai operasi militer GWOT. Hal ini sangat menguntungkan industri militer AS dan meningkatkan dominasi AS di dunia.

Kata kunci: Al Qaida, 911, dominasi AS, perang global melawan terorisme, sekuritisasi

\section{Pendahuluan}

Perang global melawan terorisme atau Global War on Terrorism (selanjutnya disingkat GWOT) dideklarasikan Presiden AS, George W. Bush, pada tanggal 20 September 2001. Dalam pidatonya di depan Kongres AS, Bush mengatakan bahwa AS akan melakukan perang panjang melawan terorisme, dengan mengerahkan semua sumber daya, mulai dari diplomasi, intelijen (every tool of intelligence), penegakan hukum (every instrument of law enforcement), pengaruh keuangan (every financial influence), dan segala senjata yang diperlukan (every necessary weapon of war).

Deklarasi perang ini dilakukan sembilan hari pasca aksi teror beruntun yang terjadi di AS pada 11 September 2001 (selanjutnya disebut 911). Kejadian ini secara total menewaskan 2997 orang, dengan perincian; 2764 tewas akibat serangan dua pesawat UA175 and AA11 di gedung World Trade Center, 189 tewas dalam serangan pesawat AA77 di Pentagon, dan 44 tewas akibat serangan pesawat UA93 di Shanksville.

Hanya beberapa jam setelah kejadian itu, pemerintahan Bush mengumumkan bahwa serangan itu merupakan serangan teroris. Bush dalam pidatonya menyatakan bahwa ia akan mengerahkan seluruh sumber daya intelijen dan aparat penegakan hukum untuk menemukan siapa yang bertanggung jawab atas serangan tersebut dan mengadilinya. Meskipun belum ada penyelidikan, Bush sudah mengisyaratkan bahwa ada negara asing yang 'melindungi' para teroris.

Bush mengatakan, "We will make no distinction between the terrorists who committed these acts and those who harbor them." [Kami tidak akan membedakan antara teroris yang melakukan aksi teror ini dan 'mereka' yang menjadi pangkalan dari jaringan teroris itu.] (Bush, 2001) 
Pernyataan keras Bush diikuti oleh statemen-statemen pejabat dan politisi AS lainnya serta oleh media-media mainstream AS yang kemudian ditayang ulang oleh media-media di seluruh dunia. Dorongan untuk berperang melawan teror digemakan. New York Times, sehari setelah 911, misalnya, menulis, “...dalam masa perang teror, menunggu bukti absolut adalah berbahaya. Ketika kita telah memastikan bases and camps para penyerang kita, kita harus menghancurleburkan merekameminimalisasi namun menerima jatuhnya korban jiwa yang niscaya terjadi-dan bertindak terang-terangan maupun tersembunyi untuk mendestabilisasi negaranegara tempat berlindungnya para teroris" (Safire, 2001).

Kongres kemudian menyetujui anggaran sebesar 22,9 miliar US Dollar untuk mendanai perang di Afghanistan. Pada tanggal 7 Oktober 2001, AS secara resmi memulai serangannya ke Afghanistan. NATO kemudian bergabung dalam operasi militer AS di Afghanistan. Pada bulan Desember 2001, Taliban kehilangan kekuasaannya di Afghanistan lalu AS membentuk pemerintahan interim yang dipimpin Hamid Karzai. (Karzai kemudian menang dalam pemilu presiden yang diadakan tahun 2004). Sementara itu, Osama bin Laden yang dituduh AS sebagai pelaku teror 911 berhasil lari dan menyembunyikan diri, sehingga AS terus melanjutkan peperangan untuk mencari Bin Laden dan menumpas Al Qaida.

Pada tahun 2008, Barrack Obama terpilih menjadi Presiden AS. Meskipun dalam masa kampanye, ia mengecam kebijakan perang Georg W. Bush dengan janji akan menghentikan perang dan lebih menggunakan kekuatan diplomasi dibanding kekuatan militer, namun Obama tetap melanjutkan GWOT. Pada tanggal 27 Maret 2009, Presiden Obama mengumumkan rencana militer terbarunya: Perang Afganistan-Pakistan. Seperti yang dulu dilakukan Bush, Obama menggunakan tragedi pengeboman gedung WTC 11 September 2001 sebagai alasan perang.

Di akhir masa kekuasannya, terbukti bahwa perang yang dilancarkan Obama jauh lebih luas daripada George W. Bush. Obama melakukan perang di 8 negara, yaitu Irak, Afghanistan, Pakistan, Somalia, Yaman, Suriah, Kamerun, dan Uganda. Dana yang dihabiskan Obama untuk perang adalah 866 miliar Dollar AS, sementara Bush menghabiskan 811 miliar Dollar AS. Selain itu, AS mengirimkan unit khusus militernya (special force) ke Suriah (Del Man, 2016).

Pada 20 Januari 2017, Donald Trump menjabat sebagai Presiden AS ke45, menggantikan Obama. Sebagaimana Obama, dalam kampanyenya, Trump mengecam kebijakan perang pemerintah AS dan berjanji akan menghentikan 
perang serta lebih fokus pada penguatan ekonomi dalam negeri. Namun tetap saja setelah terpilih, Trump masih melanjutkan GWOT.

Setelah berlalu 17 tahun, perang global melawan terorisme yang dicanangkan AS ternyata belum berhasil membuat dunia lebih aman. Presiden AS terpilih terusmenerus menggunakan isu terorisme sebagai ancaman bagi keamanan nasional AS demi menggalang dukungan publik dan Kongres untuk melanjutkan serangan militer ke berbagai negara. Dalam artikel ini, penulis akan membahas fenomena ini dengan menggunakan teori sekuritisasi, untuk menjawab pertanyaan apakah terorisme benar-benar mengancam keamanan masyarakat AS, atau adakah faktorfaktor lain yang melatarbelakangi keberlanjutan kebijakan GWOT AS?

\section{Sekuritisasi Isu Terorisme}

Studi sekuritisasi bertujuan untuk memahami aktor atau pelaku tindakan sekuritisasi (securitizing actors), apa ancaman yang diidentifikasi oleh aktor (existential threat), siapa yang terancam dan perlu dilindungi (referent object), apa perkataan yang disampaikan securitizing actors (speech act), siapa audience (publik yang menjadi target speech act, atau dipersuasi, agar percaya bahwa ada ancaman), mengapa sekuritisasi dilakukan, dan bagaimana hasil kebijakan tersebut.

Teori sekuritisasi pertama kali disampaikan oleh Barry Buzan et al. (1998) yang menjelaskan fenomena politik dimana pejabat negara memilih sebuah isu, lalu melalui serangkaian pidato atau pernyataan (speech act), isu tersebut dibawa ke ranah keamanan dan diidentifikasi sebagai ancaman keamanan sehingga negara dibenarkan melakukan tindakan-tindakan militer dalam penanganan isu tersebut.

Kondisi khusus ancaman keamanan memberikan justifikasi bagi penggunakan tindakan luar biasa dalam penanganannya. Seruan akan adanya masalah keamanan menjadi kunci bagi legitimasi penggunaan kekuatan [militer] tetapi secara umum hal ini membuka jalan bagi negara untuk memobilisasi, atau mengambil kekuasaan khusus, untuk menangani ancaman yang ada. Secara tradisional, dengan mengatakan 'keamanan', seorang wakil negara mengumumkan adanya kondisi darurat lalu mengklaim hak untuk menggunakan cara apapun yang diperlukan untuk menghalangi ancaman tersebut (Buzan, et al. 1998:21).

Dengan demikian, sekuritisasi adalah bentuk ekstrim dari politisasi. Pengambil kebijakan negara memiliki otoritas untuk memilih apakah sebuah isu tidak ditangani, 
atau ditangani dengan kebijakan politik, atau yang paling ekstrim, dinyatakan sebagai ancaman keamanan dan dilakukan langkah-langkah di luar prosedur politik normal. Aksi-aksi teror umumnya dianggap sebagai ancaman nyata (existential threat) sehingga sumber daya yang dikerahkan untuk menanganinya sangat besar, jauh lebih besar daripada penanganan bencana banjir rutin di sebuah wilayah, atau rendahnya literasi anak sekolah, misalnya.

Menurut Buzan, sekuritisasi dapat dianalisis secara langsung dan tidak diperlukan indikator. Cara menganalisisnya adalah dengan mempelajari wacana dan konstelasi politik yang berkembang yang melatarbelakangi kebijakan sekuritisasi itu. "Jika dengan sebuah argumen mengenai prioritas dan urgensitas sebuah ancaman, para aktor mampu melanggar prosedur atau aturan yang seharusnya dipatuhinya, maka kita sedang menyaksikan kasus sekuritisasi" (Buzan, et al. 1998:25)

\section{Speech Act 3 Presiden: Bush, Obama, Trump}

Dalam pidatonya di depan Kongres AS pada 20 September 2001, Presiden George W. Bush menyatakan bahwa pelaku teror 911 adalah 'musuh kebebasan' dan telah 'melakukan perang terhadap AS'. Selain itu, menurut Bush, kejadian ini adalah kejadian yang sangat luar biasa dan belum pernah terjadi sepanjang sejarah AS.

On September the 11th, enemies of freedom committed an act of war against our country. Americans have known wars, but for the past 136 years they have been wars on foreign soil, except for one Sunday in 1941. Americans have known the casualties of war, but not at the center of a great city on a peaceful morning.

Americans have known surprise attacks, but never before on thousands of civilians.

All of this was brought upon us in a single day, and night fell on a different world, a world where freedom itself is under attack.

Kemudian Bush menyatakan telah mengumpulkan bukti-bukti yang menunjukkan bahwa pelaku teror 911 adalah AI Qaida. la akan mengerahkan seluruh sumber daya, mulai dari diplomasi, intelijen, keuangan, hingga segala jenis senjata yang diperlukan untuk menghancurkan jaringan teror Al Qaida di seluruh dunia. Bush menyatakan bahwa GWOT berbeda dengan perang yang pernah dilakukan AS sebelumnya dan diperkirakan akan ada korban di pihak tentara AS, "It will not look like the air war above Kosovo two years ago, where no ground troops were used and 
not a single American was lost in combat....Our response involves far more than instant retaliation and isolated strikes."

Bush juga mengancam negara-negara yang disebutnya melindungi terorisme (provide aid or safe haven to terrorism). Menurut Bush, "Semua negara di semua kawasan kini memiliki pilihan keputusan: apakah Anda bersama kami, atau Anda bersama teroris" (Bush, 2001).

Beberapa hari sebelumnya, yaitu pada 14 September 2001 (3 hari setelah 911), Kongres AS mengesahkan resolusi The Authorization for Use of Military Force (AUMF) yang antara lain isinya:

"That the President is authorized to use all necessary and appropriate force against those nations, organizations, or persons he determines planned, authorized, committed, or aided the terrorist attacks that occurred on September 11, 2001, or harbored such organizations or persons, in order to prevent any future acts of international terrorism against the United States by such nations, organizations or persons" (GPO, 2001).

Dengan demikian, Presiden AS diberi kekuasaan penuh oleh Kongres untuk menyerbu negara, organisasi, atau orang yang menurutnya telah merencanakan, melakukan, mendanai aksi teror 911. Dengan demikian, telah terjadi hal-hal di luar prosedur normal, yang menyertai speech act yang dilakukan Bush dan dijadikannya isu terorisme sebagai isu keamanan nasional dan global.

Setelah Presiden Obama menjadi presiden, ia memerintahkan stafnya untuk mengganti frasa GWOT menjadi Overseas Contingency Operations (OCO). Sebelumnya, pada era Bush, kritik terhadap frasa GWOT juga telah disampaikan, antara lain oleh Jenderal Donald Rumsfeld yang merupakan salah satu arsitek GWOT. Rumsfeld menyarankan agar Bush mengganti GWOT menjadi "global struggle against violent extremism" (GSave). (Burkeman, 2009).

Namun demikian, perubahan istilah tidak mengubah kebijakan perang melawan terorisme global. "We are indeed at war with al-Qaida and its affiliates," demikian kata Obama beberapa bulan setelah menjabat. Kata 'its affiliates' mencakup kelompok teror yang berjejaring dengan Al Qaida dan mereka ada di berbagai penjuru dunia. Pemerintahan Obama juga melakukan serangan dengan menggunakan drone (pesawat pengebom tanpa awak) ke berbagai negara sehingga menimbulkan jatuhnya warga sipil. Penggunaan drone dilakukan karena lebih murah dan serangan terhadap target 'teroris' bisa dilakukan tanpa 
pengiriman pasukan. Dengan demikian, pada praktiknya, AS tetap melakukan GWOT (Shapiro, 2013).

Pada tanggal 27 Maret 2009, Presiden Obama mengumumkan rencana militer terbarunya: Perang Afganistan-Pakistan. Seperti yang dulu dilakukan Bush, Obama menggunakan tragedi pengeboman gedung WTC 11 September 2001 sebagai alasan perang.

"Saya mengingatkan semua orang, AS tidak memilih untuk berperang di Afghanistan," kata Obama. "Hampir 3000 rakyat kita terbunuh pada 11 September 2001, padahal mereka tidak melakukan apapun selain menjalankan aktivitas kehidupan sehari-hari. ...Saya ingin rakyat Amerika memahami bahwa kita memiliki sebuah tujuan dan fokus yang jelas: untuk mengacaukan, membongkar, dan mengalahkan al-Qaida di Pakistan dan Afghanistan, dan untuk mencegah mereka kembali ke negara itu di masa depan" (Obama, 2009).

Pasukan yang dipimpin AS pada tahun 2001 telah berhasil menggulingkan pemerintahan militan Taliban, tapi AS mengklaim bahwa banyak di antara pasukan Taliban yang melarikan diri dan membangun kekuatan kembali di perbatasan Pakistan. Karena itulah Obama mengatakan, perbatasan Afghan-Pakistan sebagai tempat paling berbahaya bagi orang AS (For the American people, this border region has become the most dangerous place in the world) (Obama, 2009).

Sementara itu, untuk audience di negara-negara Muslim, Obama menjustifikasi GWOT dengan menyebutkan bahwa terorisme yang dilakukan Al Qaida adalah existential threat bagi kaum Muslimin. Dalam pidatonya di Kairo tanggal 4 Juni 2009, Obama bahkan mengutip ayat Al Quran yang menyatakan 'siapa yang membunuh satu orang, seakan-akan ia membunuh seluruh umat manusia; dan siapa yang menyelamatkan satu orang, seakan-akan ia menyelamatkan seluruh umat manusia' (Al Quran, Al Maidah:32).

Over seven years ago, the United States pursued al Qaeda and the Taliban with broad international support. We did not go by choice, we went because of necessity. I am aware that some question or justify the events of 9/11. But let us be clear: al Qaeda killed nearly 3,000 people on that day. The victims were innocent men, women and children from America and many other nations who had done nothing to harm anybody.

...They have killed people of different faiths - more than any other, they have killed Muslims. Their actions are irreconcilable with the rights of human beings, the 
progress of nations, and with Islam. The Holy Koran teaches that whoever kills an innocent, it is as if he has killed all mankind; and whoever saves a person, it is as if he has saved all mankind. (New York Times, 2009).

Berbeda dengan Bush yang pernah menggunakan kata 'crusade' (Perang Salib) saat meluncurkan GWOT, Obama menggunakan retorika yang pro-Islam dan bahkan mengajak dunia Islam untuk bersama-sama AS bertempur melawan terorisme. Obama menyatakan perang, "We are at war, we are at war against al-Qaeda....We will do whatever it takes to defeat them"dan di saat yang sama, kepada audience kaum Muslimin, Obama mengatakan "Saya menyerukan kepada mayoritas Muslim yang menolak al-Qaeda untuk menyadari bahwa terorisme tidak menawarkan apapun selain visi yang gagal tentang kedukaan dan kematian, termasuk pembunuhan terhadap sesama muslim, dan AS berdiri bersama mereka yang mencari keadilan dan kemajuan" (Spillius, 2010).

Dalam pidato pertamanya saat diangkat sebagai Presiden AS, Donald Trump mengatakan, "We will reinforce old alliances and form new ones - and unite the civilized world against Radical Islamic Terrorism, which we will eradicate completely from the face of the Earth." (Trump, 2017).

Dalam pidatonya tanggal 21 Agustus 2017, Trump menyatakan:

"... that nearly 16 years after September 11 th attacks, after the extraordinary sacrifice of blood and treasure, the American people are weary of war without victory.

...9/11, the worst terrorist attack in our history, was planned and directed from Afghanistan because that country was ruled by a government that gave comfort and shelter to terrorists. A hasty withdrawal would create a vacuum that terrorists, including ISIS and al Qaeda, would instantly fill, just as happened before September 11 th.

... I concluded that the security threats we face in Afghanistan and the broader region are immense. Today, 20 U.S.-designated foreign terrorist organizations are active in Afghanistan and Pakistan -- the highest concentration in any region anywhere in the world.

...In Afghanistan and Pakistan, America's interests are clear: We must stop the resurgence of safe havens that enable terrorists to threaten America, and we must prevent nuclear weapons and materials from coming into the hands of terrorists and being used against us, or anywhere in the world for that matter." (Politico, 2017) 
Dengan demikian, sebagaimana Bush dan Obama, Trump tetap menjadikan terorisme sebagai existential threat bagi warga AS dan atas alasan itu ia melanjutkan perang melawan terorisme, terutama di Afghanistan dan Pakistan. Secara eksplisit Trump menyebut radical Islamic terrorism sebagai musuh yang dihadapi AS dan kebijakan yang diambil pemerintahan AS adalah memberlakukan Muslim travel ban.

Pada 25 September 2017, Trump mengumumkan pembatasan masuk warga Chad, Iran, Libya, Korea Utara, Somalia, Suriah, Venezuela, dan Yaman ke AS. Alasan yang disampaikan Trump adalah masalah keamanan. Dengan kata lain, Trump memposisikan warga dari 7 negara tersebut sebagai existential threat. Trump menulis di Twitter-nya pada 25 September 2017, "Making America Safe is my number one priority. We will not admit those into our country we cannot safely vet." Pernyataan resmi Gedung Putih mengenai hal ini menyebutkan bahwa travel ban adalah, "critical step toward establishing an immigration system that protects Americans' safety and security in an era of dangerous terrorism and transnational crime." (Jarret and Tatum, 2017).

\section{Kebijakan Perang 3 Presiden (Bush, Obama, Trump)}

Menurut Amadeo (2017), pemerintah AS telah meminta mengeluarkan dana sebesar 1998,9 miliar Dollar AS untuk GWOT. Pendanaan itu meliputi 3 komponen utama, yaitu bujet untuk Overseas Contingency Operations (OCO), bujet untuk Kementerian Pertahanan, dan bujet untuk Departemen Urusan Veteran (untuk menangani tentara yang terluka).

Berikut ini daftar dana GWOT dari tahun ke tahun dan aksi penting yang dilakukan pemerintah AS pada tahun tersebut.

Tahun 2001 : total dana 31 miliar Dollar AS; pada tahun ini AS menyerang Afghanistan, terutama posisi-posisi Taliban dengan tuduhan telah menyembunyikan pimpinan Al Qaida, Osama bin Laden. Akibat serangan ini, Taliban kehilangan kekuasaannya di Afghanistan pada Desember 2001 sementara bin Laden dikabarkan melarikan diri ke Pakistan. Pemerintahan interim dibentuk dengan dipimpin Hamid Karzai.

Tahun 2002 : total dana 59,1 miliar Dollar AS; pemerintah Bush meminta Kongres menyetujui perang ke Irak dengan alasan ada data intelijen yang menunjukkan bahwa Presiden Irak, Saddam Hussein, membuat senjata pembunuh massal. Pada bulan November, Kongres AS mengesahkan Homeland Security Act yang melegalkan berdirinya sebuah institusi khusus setingkat kementerian untuk menangani masalah terorisme di dalam negeri. 
Tahun 2003 : total dana 111,9 miliar Dollar AS; invasi ke Irak dimulai pada tanggal 19 Maret dan Saddam terguling pada bulan April. AS kemudian menyerahkan Afghanistan dan Irak kepada pasukan perdamaian NATO.

Tahun 2004 : total dana 105 miliar Dollar AS; kondisi di Irak dan Afghanistan masih tereskalasi akibat serangan-serangan dari milisi lokal. AS masih menempatkan pasukannya di kedua negara untuk 'menjaga keamanan'.

\section{Tahun 2005 : total dana 102,3 miliar Dollar AS}

Tahun 2006 : total dana 127 miliar Dollar AS; pemerintahan baru Afghanistan terbentuk namun masih kesulitan menjaga keamanan sementara aksi-aksi kekerasan meningkat. Di Irak, tentara AS mengeksekusi Saddam Hussein.

Tahun 2007 : total dana 192,5 miliar Dollar AS; AS mengirim 20.000 tentara tambahan ke Irak untuk menjaga keamanan hingga pemerintahan Irak yang baru terbentuk mampu mengendalikan situasi.

Tahun 2008: total dana 235,6 miliar Dollar AS; kekerasan meningkat di Afghanistan setelah tentara AS membunuh warga sipil. Bush mengumumkan bahwa tentara AS akan sepenuhnya ditarik dari Irak pada 2011.

Tahun 2009 : total dana 197,1 miliar Dollar AS; Presiden Obama dilantik. la mencanangkan perang lanjutan ke perbatasan Afghanistan-Pakistan, mengirimkan tambahan 17.000 tentara ke Afghanistan pada bulan April dan menjanjikan akan mengirim 30.000 tentara lagi pada bulan Desember. He focused on attacking resurgent Taliban and al-Qaida forces on the border with Pakistan. Obama juga mengumumkan bahwa tentara AS akan sepenuhnya ditarik dari Irak pada 2011.

Tahun 2010: total dana 181 miliar Dollar AS; Obama mengurangi jumlah tentara di Irak, lalu mengirim tentara tambahan ke Afghanistan.

Tahun 2011: total dana 162,4 miliar Dollar AS; pasukan khusus AS (Special Forces) membunuh Osama bin Laden pada 1 Mei 2011. Obama mengumumkan akan menarik 10.000 tentara dari Afghanistan pada akhir 2011 dan 23.000 lainnya pada akhir 2012. Sementara tentara dari Irak ditarik pada Desember.

Tahun 2012: total dana 119,6 miliar Dollar AS; Obama mengumumkan hanya menyisakan 70.000 tentara di Afghanistan.

Tahun 2013 : total dana 49,6 miliar Dollar AS; peran tentara AS di Afghanistan hanya melatih dan mendukung tentara lokal. 
Tahun 2014: total dana 88 miliar Dollar AS; Obama mengumumkan penarikan final tentaranya dari Afghanistan, menyisakan hanya 9.800 personil.

\section{Tahun 2015 : total dana 67 miliar Dollar AS}

Tahun 2016 : total dana 89,5 miliar Dollar AS; tentara kembali dikirim ke Irak dengan tujuan melatih tentara lokal melawan ISIS. Kementerian Pertahanan juga meminta dana untuk pelatihan di Afghanistan, serta melatih dan mempersenjatai pasukan pemberontak Suriah. Dana ini juga untuk mendukung NATO serta respon bagi ancaman terorisme.

Tahun 2017 : total dana 80,3 miliar Dollar AS; Kementerian Pertahanan meminta dana 58,8 miliar Dollar AS untuk Operasi 'Freedom Sentinel' di Afghanistan, Operasi 'Inherent Resolve' di Irak dan Suriah, serta mendukung Eropa dan upaya konter-terorism. Presiden Trump juga meminta tambahan dana 24,9 miliar untuk Kementerian Pertahanan dan 5,1 miliar untuk kemungkinan perang (OCO) melawan ISIS.

\section{Terorisme: Existensial Threat untuk Siapa?}

GWOT telah dilancarkan Presiden George W. Bush ketika penyelidikan 911 belum tuntas. Komisi Penyelidikan 911 baru dibentuk oleh Bush pada akhir tahun 2002 dan baru menyerahkan hasil penyelidikan mereka pada tahun 2004. Masih banyak pertanyaan yang belum terjawab oleh laporan Komisi Penyelidikan 911 itu. Niels H. Harrit dari Departemen Kimia Copenhagen University (Denmark) dan Jeffrey Farrer dari Departemen Fisika dan Astronomi Brigham Young University (AS) bersama beberapa pakar teknik sipil meakukan penelitian yang hasilnya dimuat di The Open Chemical Physics Journal (2009). Dalam artikel tersebut, Niels et al. menyatakan bahwa ditemukan lapisan tipis debu bom super thermite di lokasi reruntuhan WTC.

"... we conclude that the red layer of the red/gray chips we have discovered in the WTC dust is active, unreacted thermitic material, incorporating nanotechnology, and is a highly energetic pyrotechnic or explosive material."

Kecurigaan keterlibatan bom (gedung WTC tidak semata-mata runtuh akibat ditabrak sebuah pesawat) juga muncul dari kalangan praktisi pemadam kebakaran. Sebuah majalah profesional terkemuka, Fire Engineering, yang berusia lebih dari 100 tahun, telah menulis keraguan atas teori yang dikemukakan Federal Emergency Management Agency (FEMA) bahwa 'gedung WTC runtuh akibat ditabrak pesawat'. Editor majalah yang secara rutin menerbitkan tulisan analisis teknis atas berbagai 
kebakaran besar ini, William Manning, menyerukan agar personil pemadam kebakaran dan para insinyur di bidang ini untuk meminta Kongres agar melakukan penyelidikan mendalam atas bekas reruntuhan WTC. Menurut Manning, "Kerusakan struktural dari pesawat dan ledakan akibat bahan bakar pesawat tidak cukup untuk meruntuhkan kedua menara itu." Manning juga mengkritik tindakan pemerintah yang segera memotong-motong baja di reruntuhan WTC dan menjualnya ke China sebelum dilakukan penyelidikan.

"Penghancuran barang bukti menunjukkan pengabaian yang luar biasa dari pejabat pemerintah terhadap nilai penyelidikan ilmiah yang teliti terhadap keruntuhan gedung terbesar dalam sejarah dunia. Dalam standar nasional untuk penyelidikan kebakaran, tidak akan ditemukan kebolehan penghancuran barang bukti untuk bangunan yang melebihi 10 lantai. ... Jelas, ada pertanyaanpertanyaan yang membutuhkan jawaban. Berdasarkan besarnya insiden itu, penyelidikan forensik yang menyeluruh dengan mengerahkan seluruh sumber daya, sangat penting." (Bollyn, 2002)

Thierry Meyssan, seorang jurnalis asal Prancis, dalam bukunya, 9/11 The Big Lie, mempertanyakan beberapa hal dari kejadian ini. Antara lain, Meyssan menulis bahwa secara teknis, penabrakan pesawat jenis Boeing ke menara WTC sangat sulit terjadi.

"Sebelum tiba di New York, pesawat-pesawat itu harus menurunkan ketinggian mereka sehingga pilot dapat melihat menara secara berhadapan, alih-alih melihat dari atas. Dilihat dari langit, sebuah kota akan tampak menyerupai selembar peta dan semua acuan visual yang lazim menjadi hilang. Untuk menabrak menara, pesawat perlu dipraposisikan pada ketinggian sangat rendah. ... Mengingat kemampuan manuver pesawat jenis ini rendah, adalah sebuah prestasi luar biasa bagi seorang pilot yang berpengalaman [untuk bisa turun pada ketinggian yang sangat rendah], apalagi bagi seorang pilot magang." (33)

Meyssan mengemukakan kemungkinan bahwa pesawat Boeing itu dapat ditabrakkan dengan sedemikian tepat sasaran karena menggunakan teknologi pengendalian pesawat tanpa awak. Selain itu, Meyssan mengutip pakar terkemuka dari New Mexico Institute of Mining and Technology,Van Romero, yang menyatakan bahwa runtuhnya menara WTC hanya mungkin diakibatkan oleh ledakan (bukan karena ditrabrak pesawat). (34-35) 
Terlepas dari berbagai keraguan yang dikemukakan berbagai kalangan, speech act yang dikemukakan pemerintah AS-lah yang berpengaruh secara global. Pemerintah AS melalui speech act telah menjadikan terorisme sebagai existential threat bagi domestik AS, dan bagi masyarakat dunia. Bush berhasil menggerakkan Dewan Keamanan PBB, NATO, dan Uni Eropa untuk bergerak cepat membangun kebijakan counterterrorism. AS berhasil menggalang 33 negara untuk bergabung dalam pasukan koalisi yang langsung dipimpin AS sendiri. Pada Oktober 2001, GWOT pun dimulai dengan menyerbu Afghanistan dimulai dengan misi menumbangkan Taliban dan menangkap Osama bin Laden. Selanjutnya, pada 2002, pasukan khusus AS bekerjasama dengan militer Philipina dengan misi mengusir kelompok Abu Sayyaf dan Jamaah Islamiyah dari Pulau Basilan. Tahun yang sama, perang juga dilancarkan ke beberapa kawasan di Afrika yang juga dituduh menjadi basis teroris. Tahun 2003, perang kembali diluncurkan ke Irak dengan misi menggulingkan Saddam Husein atas tuduhan menyimpan senjata pembunuh massal yang mengancam keamanan dunia. Selain perang fisik, AS juga menggalang dukungan internasional untuk bersama-sama melancarkan GWOT di wilayah masing-masing.

Di sini muncul pertanyaan, Waron Terroryang diinisiasi Bush merupakan reaksi dari serangan 911, yaitu existential threat bagi bangsa AS. Lalu, mengapa pemerintah AS melakukan speech act kepada audience global dan menjadikan pelaku penyerangan 911 di AS sebagai existential threat bagi seluruh dunia?

\section{Terorisme dan Tujuan AS Melakukan Sekuritisasi}

Untuk menjawab pertanyaan tersebut, kita perlu melihat dulu apa definisi terorisme. Hingga kini belum ada kesepakatan global mengenai definisi terorisme. Berbagai lembaga, organisasi, dan cendekiawan memberikan definisi mereka masing-masing atas terorisme. Menurut Crenshaw (2007:68) meskipun PBB telah mengeluarkan berbagai konvensi anti terorisme, namun negara-negara anggota PBB hingga kini tidak bersepakat atas definisi terorisme karena dua alasan. Pertama, Negara-negara anggota PBB masih belum bersepakat apakah negara dikategorikan teroris bila angkatan bersenjata mereka melakukan serangan kepada warga sipil. Kedua, terkait dengan justifikasi moral terhadap aksi kekerasan; apakah gerakan perlawanan melawan pendudukan asing (misalnya di Palestina atau Irak atau Afghanistan) dikategorikan teroris. Namun kemudian United Nations High-Level Panel on Threats, Challenges, and Change menyebutkan bahwa terorisme adalah: 
"any action ... that is intended to cause death or serious bodily harm to civilians or non-combatants, when the purpose of such act by its nature or context, is to intimidate a population, or to compel a Government or an international organization to do or to abstain from doing any act." (Crenshaw, 2007:68)

Crenshaw menyatakan bahwa terorisme bukan hanya ancaman bagi AS melainkan bagi masyarakat global. Penyebabnya, intensitas ancaman tidak hanya tergantung pada konsekuensi material (misalnya, jumlah orang yang tewas atau jumlah gedung yang hancur akibat terorisme), melainkan juga pada kondisi ketidakpastian akibat ancaman itu. Menurutnya, bagi publik, terorisme sangat menakutkan karena sifatnya yang tak terduga (unpredictable). Terorisme sering menjadikan masyarakat sipil sebagai target dan masing-masing tidak tahu, apakah orang yang duduk di sampingnya di kereta, bis, atau pesawat adalah teroris. Aksi-aksi terorisme, yang skalanya kecil sekalipun, menjadi pengingat konstan betapa rapuhnya keamanan mereka (Crenshaw, 2007:77). Artinya, aspek subjektif dari ancaman ini, misalnya ketakutan dan kengerian, sama pentingnya dengan aspek objektif.

Terorisme dirasakan sebagai ancaman oleh referent object, yaitu masyarakat di berbagai negara, terutama negara Barat, karena peran media. Media massa sangat masif menyebarkan berita mengenai terorisme sehingga terorisme tampak seperti bahaya yang riil dan ada (real and present danger) padahal jumlah orang yang meninggal karena sakit, atau kecelakaan, atau kelaparan, jauh lebih banyak. Selain itu, tindakan AS yang mendeklarasikan GWOT lalu menyerang Afghanistan, Irak, dan negara-negara lain telah memicu munculnya persepsi global bahwa terorisme adalah sumber bahaya dan ketidakamanan yang mengancam setiap saat (Crenshaw, 2007:78).

Di sisi lain, pasca 911 tahun 2001, jaringan Al Qaida terlihat menyebar ke berbagai penjuru dunia, mulai dari Kenya, Tanzania, Maroko, Tunisia, Arab, Mesir, Yaman, Jordan, Irak, Afghan, Turki, Spanyol, Inggris, Pakistan, Indonseia, dan Philipina. Aksiaksi teror sporadis muncul di berbagai negara. Kedua faktor ini, upaya speech act pemerintah AS dan aksi-aksi teror sporadis Al Qaida memberikan justifikasi bagi tindakan unilateral AS melakukan intervensi militer di berbagai negara dengan alasan GWOT.

Bila kita mencermati data korban GWOT yang dilancarkan AS di negara-negara yang disinyalir sebagai habitatjaringan AI Qaida, kita akan menemukan bahwa korban terbesar adalah masyarakat sipil. Jumlah mereka jauh melampaui korban langsung dari aksi teror yang dilakukan jaringan AI Qaida. Pada tahun 2015, Physicians for Social 
Responsibility (PRS) menerbitkan hasil penelitian mereka atas jumlah korban akibat GWOT. Menurut laporan ini, total korban tewas selama 10 tahun GWOT minimalnya 1,3 juta dan bisa mencapai 2 juta (karena bervariasinya laporan yang disampaikan oleh berbagai lembaga).

\section{Perbandingan Jumlah Korban Teror Al-Qaida (Muslim - Barat)}

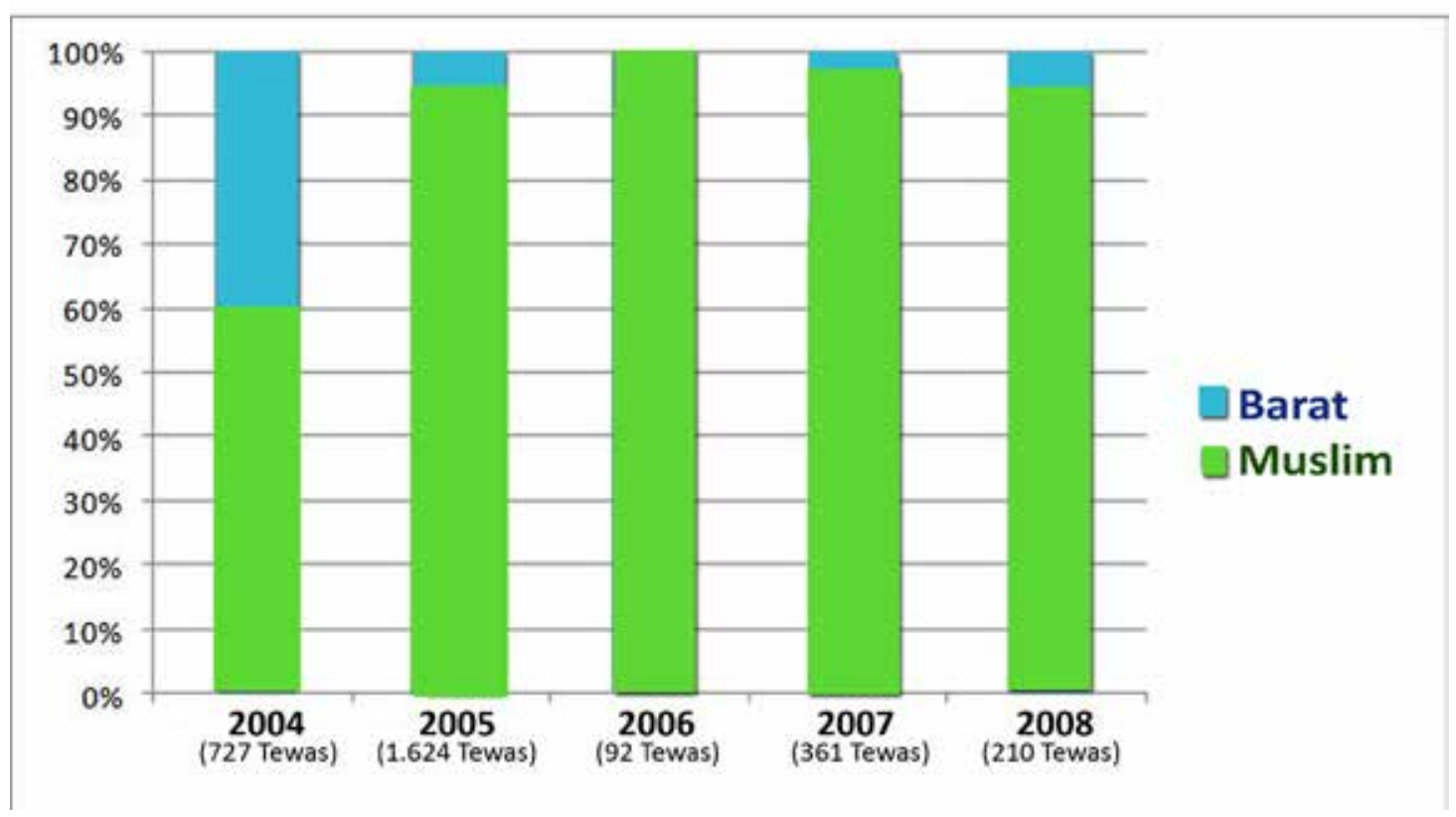

Sumber tabel: Helfstein, S., et al (2009)

Afghanistan

Berikut ini tabel angka korban GWOT di Afghanistan (Okt.2001-akhir 2013)

\begin{tabular}{|l|l|}
\hline Warga sipil dan kombatan & $\begin{array}{l}\text { Jumlah yang tewas secara } \\
\text { langsung }\end{array}$ \\
\hline Kematian akibat serangan & $106.000-170.000$ \\
\hline Jurnalis & 22 \\
\hline Pekerja LSM & 281 \\
\hline Aparat keamanan Afghanistan & 15.000 \\
\hline Aparat keamanan swasta AS & 3.000 \\
\hline Tentara ISAF dan OEF & 3409 \\
\hline Pekerja sipil pemerintah AS & 1700 \\
\hline Taliban & 55.000 \\
\hline Total & - 55.000 \\
\hline
\end{tabular}




\section{Pakistan}

Berikut ini tabel angka korban GWOT di Pakistan (2004-akhir 2013)

\begin{tabular}{|l|l|}
\hline Warga sipil dan kombatan & Jumlah yang tewas secara langsung \\
\hline Warga sipil Pakistan & 48.504 \\
\hline Jurnalis & 45 \\
\hline Warga sipil yang tewas akibat drone & $416-951$ \\
\hline Aparat keamanan Pakistan & 5.498 \\
\hline Militan & 26.862 \\
\hline Total & $81.325-81.860$ \\
\hline
\end{tabular}

Sumber tabel: Physicians for Social Responsibility (2015)

Catatan: jika ditambah dengan korban di kawasan AfPak (perbatasan kedua negara), estimasi yang muncul adalah 265.000-330.000 korban tewas. Angka ini terdiri dari 108.000 kombatan dan antara 157.000-221.000 non-kombatan. Artinya, jumlah orang yang 'tidak sengaja' terbunuh dalam perang GWOT 50\%-100\% lebih besar daripada jumlah kombatan (teroris).

Irak

Untuk Irak, jumlah korban menurut berbagai lembaga adalah sebagai berikut.

2003-2008: lebih dari 1 juta warga Irak tewas akibat perang, pendudukan, dan dampak tidak langsung (menurut Opinion Research Business-ORB)

2004-pertengahan 2008: 77.000 warga sipil dan aparat keamanan tewas (menurut U.S. Central Command-CENTCOM)

2003-2009: lebih dari 110.000 korban perang Irak (menurut Associated Press, bersumber dari Kementerian Kesehatan Irak dan sumber-sumber lain)

2003-2011: total warga Irak yang tewas 165.000 orang, minimalnya 125.000 di antaranya adalah warga sipil (menurut Costs of War project, Brown University).

Pemerintah AS dalam speech act-nya menyatakan bahwa terorisme (Al Qaida) adalah ancaman keamanan bagi AS. Namun bila kita melihat statistik, jumlah korban yang tewas akibat serangan Al Qaida di seluruh dunia justru lebih banyak dari kalangan non-Barat. Berikut ini tabel perbandingan jumlah korban akibat aksi terror yang dilakukan oleh AI Qaida, antara korban warga Barat dengan warga nonBarat. 


\section{Serangan Drone}

Kebijakan Presiden Obama terkait GWOT adalah mengurangi pasukan di darat dan lebih banyak menggunakan drone (pesawat tanpa awak yang mengebom targettarget dengan dikendalikan dari jarak jauh). Obama melakukan serangan drone sepuluh kali lebih banyak daripada yang dilakukan George W. Bush. Selama masa pemerintahan Obama, dilakukan 563 serangan, sebagian besarnya dengan drone di Pakistan, Somalia, dan Yaman sementara Bush hanya melakukan 57 serangan (The Bureau of Investigative Journalism, 2017).

Jumlah korban serangan tewas akibat drone antara Juni 2004 hingga September 2012 adalah 2.562-3.325 di Pakistan, dimana 474-881 adalah warga sipil, termasuk 176 anak-anak. Selain itu, ada 1.228-1362 individu yang terluka.

IHRCRC (International Human Rights and Conflict Resolution Clinic) dan GCJ (Global Justice Clinic) pada tahun 2012 menerbitkan laporan penelitian mereka terhadap 130 korban dan saksi mata serangan drone AS di Pakistan. Ada empat poin kesimpulan penelitian ini, yaitu sebagai berikut.

1. Meskipun pemerintah AS mengklaim bahwa sangat sedikit korban sipil dalam serangan drone, bukti menunjukkan bahwa serangan tersebut telah melukai dan membunuh banyak warga sipil.

2. Kebijakan AS untuk memerangi teroris dengan menggunakan drone telah merusak kehidupan warga sipil, selain jatuhnya korban jiwa dan luka. Serangan drone dilakukan siang-malam di kawasan berpenduduk di Pakistan barat laut, menyerang rumah, kendaraan, dan kawasan publik tanpa peringatan. Keberadaan drone telah membuat ketakutan, gangguan psikologis, dan trauma warga, baik itu laki-laki, wanita, dan anak-anak.

3. Klaim AS menyatakan bahwa serangan drone telah meningkatkan keamanan AS adalah ambigu. Karena, meski serangan memang membunuh terduga teroris dan mengganggu jaringan mereka, namun efektivitas serangan itu sangat diragukan. Menurut laporan, hanya 2\% dari serangan yang benar-benar mengenai target tingkat tinggi (dan sisanya mengenai warga nonteroris). Akibatnya, 74\% warga Pakistan memandang AS sebagai musuh.

4. Tindakan AS menyerang warga sipil dengan drone telah melanggar hukum internasional dan menjadi preseden berbahaya. Serangan drone telah menargetkan individual atau grup yang tidak terkait langsung dengan serangan 911 dan bukan ancaman dekat (imminent threat) bagi AS. 
GWOT yang dilancarkan AS juga menimbulkan korban di pihak militer AS. Pada Agustus 2016, tentara AS yang tewas dalam Operation Enduring Freedom dan Operation Freedom's Sentinel di Afghanistan mencapai 2.383 orang. Tentara AS yang tewas di Irak adalah 4.504 orang. Beberapa ribu warga sipil AS yang bekerja di Irak dan Afghanistan juga tewas, sehingga total keseluruhan orang AS yang tewas di kedua negara itu mencapai 10.000 orang. Selain itu 50.000 personil militer AS terluka. Padahal, pertahun rata-rata 'hanya' 6-7 orang yang tewas di AS akibat aksi terorisme berbasis agama; sementara pertahun ada 14.000-15.000 kasus pembunuhan kriminal di AS. Dengan demikian, terlihat jelas bahwa terorisme telah disekuritisasi oleh pemerintah AS. Aksi teror dengan jumlah korban yang jauh lebih sedikit dijadikan existential threat sementara kasus-kasus kriminal yang jumlah korbannya jauh lebih banyak tidak dipandang sebagai existential threat.

Dari sini, kita bisa berlanjut kepada jawaban pertanyaan, apa tujuan pemerintah AS melakukan sekuritisasi global terhadap isu terorisme?

Ada banyak analisis yang telah ditulis terkait motif AS meluncurkan GWOT. Misalnya, Robert Gilpin (2005) dalam artikel jurnalnya menulis bahwa keputusan Bush untuk menyerang Irak dipengaruhi oleh tiga faktor politik domestik, yaitu pertama, kelompok ultra-nationalists. Motif kelompok ini adalah untuk mengontrol cadangan minyak di Timur Tengah dan mempertahankan dominasi global AS. Kelompok kedua adalah neo-konservatif, yang selain memiliki tujuan serupa terkait minyak dan dominasi AS, juga menginginkan restrukturisasi radikal atas relasi geopolitik di kawasan dengan tujuan untuk menciptakan keamanan jangka panjang bagi Israel. Sementara itu, kelompok ketiga adalah konstituen yang sangat kuat di dalam negeri yang pro-perang, khususnya kelompok Kristen Evangelis.

Menurut Gilpin, kelompok ultranasionalis adalah Wakil Presiden, Richard Cheney, Menteri Pertahanan, Donald Rumsfeld, dan pejabat tinggi di Kementerian Dalam Negeri, John Bolton. Mereka meyakini bahwa dengan menguasai sumber-sumber minyak di Timur Tengah dan Asia Tengah, AS dapat menjadi penguasa global. Sementara itu, kelompok neo-konservatif, baik yang berada di dalam pemerintahan atau individu di luar, seperti Paul Wolfowitz, Richard Perle, dan Daniel Pipes, sangat mementingkan keamanan Israel. Mereka meyakini bahwa menghilangkan 'ancaman Irak' terkait dengan keamanan bagi Israel (Gilpin, 2005: 14-15).

Bila kita melihat latar belakang para tokoh ultranasionalis itu, kita akan menemukan bahwa Bush, Cheney, Rumsfeld, Wolfowitz, Rice, dan beberapa tokoh neo-con lain dalam pemerintahan Bush memiliki saham di berbagai perusahaan 
minyak. Perang melawan terorisme telah menjatuhkan korban sangat banyak, baik warga sipil di Irak, Afganistan, Pakistan, atau di tempat-tempat lain; namun di saat yang sama memberikan keuntungan raksasa bagi kaum kapitalis. Selain perusahaan-perusahaan minyak yang menangguk untung dari pengontrolan kilang-kilang minyak di Irak, perusahaan-perusahaan senjata, perusahaan keamanan swasta (private security company), dan kontraktor sipil (pembangunan infrastruktur) juga menangguk keuntungan yang luar biasa besar. Ketika perang terus-menerus berlanjut, pabrik-pabrik senjata akan terus berproduksi dan terus mendapatkan pasar; perusahaan keamanan privat terus mendapatkan order, dan perusahaan pembangunan infrastruktur terus mendapat kontrak pembangunan (rekonstruksi) di negara-negara bekas perang. Perusahaan minyak juga mengambil keuntungan besar karena harga minyak yang cenderung naik pesat bila perang di Timur Tengah meletus.

Para kapitalis 'bisnis' perang mendirikan perusahaan keamanan swasta yang mendapat order dari Pentagon untuk memberikan konsultasi resiko di kawasan konflik, melatih pasukan lokal di kawasan konflik, mengamankan gudanggudang senjata, mengawal perpindahan uang, memberikan pelayanan intelijen, mengamankan berbagai gedung-gedung, memenuhi kebutuhan persenjataan bagi perang dan pengamanan, logistik, dan bahkan penyediaan penjara dan investigasi narapidana. Di antara pejabat pemerintahan Bush yang memiliki saham di perusahaan keamanan privat adalah Dick Cheney dan Mike McConnell.

Lalu, bagaimana cara agar pemerintah negara-negara dunia bersedia bergabung dalam perang melawan terorisme? Altheide (2006) memberikan jawabannya, yaitu dengan menggunakan'politics of fear'. Sebelum bisa meluncurkan GWOT, pemerintah AS harus mendapatkan dukungan dari dalam negeri dan persetujuan perwakilan rakyat (Kongres dan Senat). Dalam rangka ini, politisi dan agen-agen pemerintah AS bekerja sama dengan media massa untuk menyebarluaskan ketakutan sehingga rakyat mau menggantungkan diri kepada agen-agen pemerintah untukmenyediakan perlindungan serta melakukan pembalasan dendam dan hukuman terhadap pelaku teror. Sumber-sumber pemberitaan media massa AS sangat bergantung kepada sumber pemerintah untuk menyediakan laporan yang bersesuaian dengan simbolsimbol ketakutan, kriminalisasi, dan korban akibat terorisme, serta ancaman terhadap AS (Altheide, 2006:114).

Menurut Altheide, “Di dunia modern, power (kekuatan) menampakkan dirinya melalui ketakutan. GWOT tidaklah dilancarkan berdasarkan perencanaan militer yang solid, trend global yang koheren, atau analisis yang meyakinkan tentang 
kepentingan nasional AS. Kebijakan GWOT berlandaskan pada ketakutan dan dijual kepada rakyat melalui politics of fear." (Altheide, 2006:207). Altheide menyatakan bahwa politics of fear didefinisikan sebagai upaya pengambil kebijakan (pemerintah) untuk mengembangkan dan memanfaatkan keyakinan dan asumsi khalayak umum tentang bahaya, resiko, dan ketakutan demi meraih tujuan tertentu. Sumber dari ketakutan itu bisa berupa otoritas, Tuhan, atau musuh internal dan eksternal (Altheide, 2006:208).

Sementara itu, Skaff (2010) mengutip Herman and O'Sullivan yang menulis bahwa terrorisme telah memberikan kesempatan bagi para pemimpin di Barat untuk menciptakan ketakutan dan irasionalitas di tengah masyarakat sehingga mereka memberikan kebebasan kepada para pemimpin itu untuk melakukan apa saja. Ketakutan terhadap terorisme efektif untuk memobilisasi massa agar mendukung aksi-aksi militer. Herman dan O'Sullivan menampilkan contoh kasus pemerintahan Reagan saat itu yang menyebarluaskan ketakutan atas ancaman terorisme dengan tujuan untuk menjustifikasi proyek pembangunan instalasi senjata yang memakan biaya sangat besar.

Seperti telah diungkapkan di atas, pada masa Bush, para kapitalis perang telah mengeruk keuntungan besar dari bisnis perang. Perekonomian AS terus berjalan karena perindustriannya terus bergerak, terutama industri militer. Karena itulah, presiden selanjutnya, baik Obama maupun Trump terus melanjutkan GWOT.

\section{Kesimpulan}

Pasca serangan teror terhadap beberapa gedung di AS, antara lain WTC, pada 11 September 2001, pemerintah AS secara aktif menyebarkan narasi bahwa pelaku serangan tersebut adalah AI Qaida. Meskipun hasil investigasi belum final dan muncul beberapa keraguan terkait barang bukti, pemerintah AS melalui speech act telah berhasil menjadikan terorisme sebagai existential threat bagi bangsa AS. Pemerintah AS mengklaim bahwa GWOT adalah demi melindungi warga AS (referent object) dan audience (masyarakat dunia) dipersuasi agar bergabung bersama AS dalam GWOT. Sebagai hasilnya, terorisme pun menjadi menjadi existential threat bagi masyarakat global. Bush berhasil menggerakkan Dewan Keamanan PBB, NATO, dan Uni Eropa untuk bergerak cepat membangun kebijakan counterterrorism. AS kemudian menggalang 33 negara untuk bergabung dalam pasukan koalisi yang langsung dipimpin AS sendiri. GWOT dimulai pada 2001, dimulai dari Afghanistan, kemudian berlanjut ke Irak dan berbagai negara. Dengan mempertimbangkan bahwa jumlah 
korban akibat kejadian-kejadian lain (seperti kriminalitas) dan jumlah korban akibat GWOT (baik warga sipil maupun tentara AS sendiri) jauh lebih besar daripada korban aksi terorisme Al Qaida dan jaringannya, perlu digali motif sesungguhnya di balik kebijakan GWOT AS. Ambisi untuk mengontrol cadangan minyak di Timur Tengah, mempertahankan dominasi global AS, melindungi keamanan jangka panjang Israel, serta mendapatkan profit bagi bisnis perang adalah di antara motif tersebut.

\section{Daftar Pustaka}

Altheide, David L. (2006). Terrorism and the Politics of Fear. Oxford: AltaMira Press

Amadeo, Kimberly. (2017). War on Terror Facts, Costs, and Timeline. The Balance. [online] Dalam: https://www.thebalance.com/war-on-terror-facts-coststimeline-3306300 [Diakses 5 Des. 2017]

Bollyn, Christopher. (2002). Fire Engineers Refute 9-11 Collapse Theory. Bollyn. [online] Dalam: http://www.bollyn.com/911\#article_11827 [Diakses 5 Des. 2017]

Bureau of Investigative Journalism. (2017). Obama's covert drone war in numbers: ten times more strikes than Bush. [online] Dalam:https://www.thebureauinvestigates. com/stories/2017-01-17/obamas-covert-drone-war-in-numbers-ten-timesmore-strikes-than-bush [Diakses 5 Des. 2017]

Burkeman, Oliver. (2009). Obama administration says goodbye to 'war on terror'. The Guardian. [online] Dalam https://www.theguardian.com/world/2009/mar/25/ obama-war-terror-overseas-contingency-operations [Diakses 1 Okt. 2017]

Bush, George W. (2001). Statement by the President in His Address to the Nation. The White House, [online] Dalam: https://georgewbush-whitehouse.archives.gov/ news/releases/2001/09/20010911-16.html [Diakses 1 Okt. 2017]

Cavallaro, James., Sonnenberg, Stephan., dan Knuckey, Sarah. (2012). Living Under Drones: Death, Injury and Trauma to Civilians from US Drone Practices in Pakistan. Stanford: International Human Rights and Conflict Resolution Clinic, Stanford Law School; New York: NYU School of Law, Global Justice Clinic.

Del Man, Edward. (2016). Obama Promised to End America's Wars-Has He?. The Atlantic. [online] Dalam https://www.theatlantic.com/international/ archive/2016/03/obama-doctrine-wars-numbers/474531/ [Diakses 1 Okt. 2017] 
Gilpin, Robert. (2005). War is Too Important to Be Left to Ideological Amateurs. International Relations. Vol. 19 (1) pp.5-18

GPO. (2001). Public Law 107-40-Sept. 18, 2001. Government Publishing Office. [online] Dalam: https://www.gpo.gov/fdsys/pkg/PLAW-107publ40/pdf/PLAW107publ40.pdf [Diakses 1 Okt. 2017]

Harrit, N., Farrer, J., Jones, S., Ryan, K., Legge, F., Farnsworth, D., Roberts, G., Gourley, J., dan Larsen, B. (2009). Active Thermitic Material Discovered in Dust from the 9/11 World Trade Center Catastrophe. The Open Chemical Physics Journal. Vol. 2 pp. 7-31. [online] Dalam https://benthamopen.com/contents/pdf/TOCPJ/TOCPJ-2-7. pdf [diakses 2 Okt. 2017]

Helfstein, S., Abdullah, N., dan Al Obaidi, M. 2009. Deadly Vanguards: A Study of al-Qa'ida's Violence Against Muslims. [online] Dalam https://ctc.usma.edu/app/ uploads/2010/10/deadly-vanguards complete I.pdf [Diakses 15 Okt. 2017]

Jarrett, L., dan Tatum, S. (2017). Trump administration announces new travel restrictions. CNN. [online] Dalam: https://edition.cnn.com/2017/09/24/politics/ trump-travel-restrictions/index.html [Diakses 4 Okt. 2017]

New York Times. (2009). Text: Obama's Speech in Cairo. New York Times. [online] Dalam https://www.nytimes.com/2009/06/04/us/politics/04obama.text.html [Diakses 1 Okt. 2017]

Obama. (2009). President Obama's Speech on Afghanistan and Pakistan. US News. [online] Dalam https://www.usnews.com/news/articles/2009/03/27/presidentobamas-speech-on-afghanistan-and-pakistan [Diakses 1 Okt. 2017]

Physicians for Social Responsibility. (2015). Body Count: Casualty Figures after 10 Years of the "War on Terror". [online] Dalam https://www.psr.org/wp-content/ uploads/2018/05/body-count.pdf [Diakses 3 Okt. 2017]

Politico. (2017). Full text: Trump's speech on Afghanistan. [online] Dalam: https:// www.politico.com/story/2017/08/21/trump-afghanistan-speech-text-241882 [Diakses 1 Okt. 2017]

Safire, William. (2001). Essay; New Day Of Infamy. New York Times. [online] Dalam https://www.nytimes.com/2001/09/12/opinion/essay-new-day-of-infamy.html [Diakses 1 Okt. 2017]

Shapiro, Ari. (2013). Obama Team Stops Saying 'Global War On Terror' But Doesn't Stop Waging It. NPR. [online] Dalam https://www.npr.org/sections/ 
itsallpolitics/2013/03/11/174034634/obama-team-stops-saying-global-war-onterror-but-doesnt-stop-waging-it [Diakses 1 Okt. 2017]

Skaff. (2010). The Terror Card: Fear is the Key to Obedience. Global Research. [online] Dalam: $\quad$ http://www.globalresearch.ca/index.php?context=va\&aid=17299 [Diakses 4 Nov. 2017]

Spillius, Alex. (2010). Barack Obama: US is at war with al-Qaeda. Telegraph. [online] Dalam: https://www.telegraph.co.uk/news/worldnews/barackobama/6950879/ Barack-Obama-US-is-at-war-with-al-Qaeda.html [Diakses 5 Okt. 2017]

Trump. (2017). Inaugural Address. The White House. [online] Dalam: https://www. whitehouse.gov/briefings-statements/the-inaugural-address/ [Diakses 5 Nov. 2017]

Washington Post, (2001). Full text of President Bush's address to a joint session of Congress and the nation. [online] Dalam: http://www.washingtonpost.com/wpsrv/nation/specials/attacked/transcripts/bushaddress 092001.html [Diakses 5 Nov.2017] 